\title{
Fractional flow reserve measurement modification with monorail pressure catheter
}

\author{
Magdalena Jędrychowska ${ }^{1}$, Rafał Januszek ${ }^{1}$, Łukasz Rzeszutko ${ }^{1}$, Dariusz Dudek ${ }^{1,2}$ \\ ${ }^{1} 2^{\text {nd }}$ Department of Cardiology and Cardiovascular Interventions, University Hospital, Krakow, Poland \\ ${ }^{2}$ Department of Interventional Cardiology, Jagiellonian University Medical College, Krakow, Poland
}

A number of symptomatic patients with coronary artery disease undergo revascularization without definite evidence that particular coronary stenosis is responsible for their symptoms [1]. Currently, the borderline coronary artery stenoses are most commonly assessed by intravascular ultrasound and fractional flow reserve (FFR) alongside with quantitative coronary angiography [2]. FFR measurement, as performed by pressure wire (PW), requires its multiple removals during FFR and percutaneous coronary intervention (PCI), and results in a relatively high signal drift with loss of accuracy. The novel exchange microcatheter (RXi) was invented to assess FFR in a safer mode [3, 4].

A 61-year-old man was admitted to hospital with exertional stenocardia. The patient underwent myocardial infarction in 1988 and coronary artery bypass grafting operation in 1999. Angiography revealed total occlusion of the left anterior descending artery (LAD), as previously. In the right coronary artery (RCA) occurred disseminated, multi-segmental stenoses up to $40 \%$ with borderline stenosis of $60 \%$ in the distal portion (Fig. 1A). The aorto-marginal saphenous vein

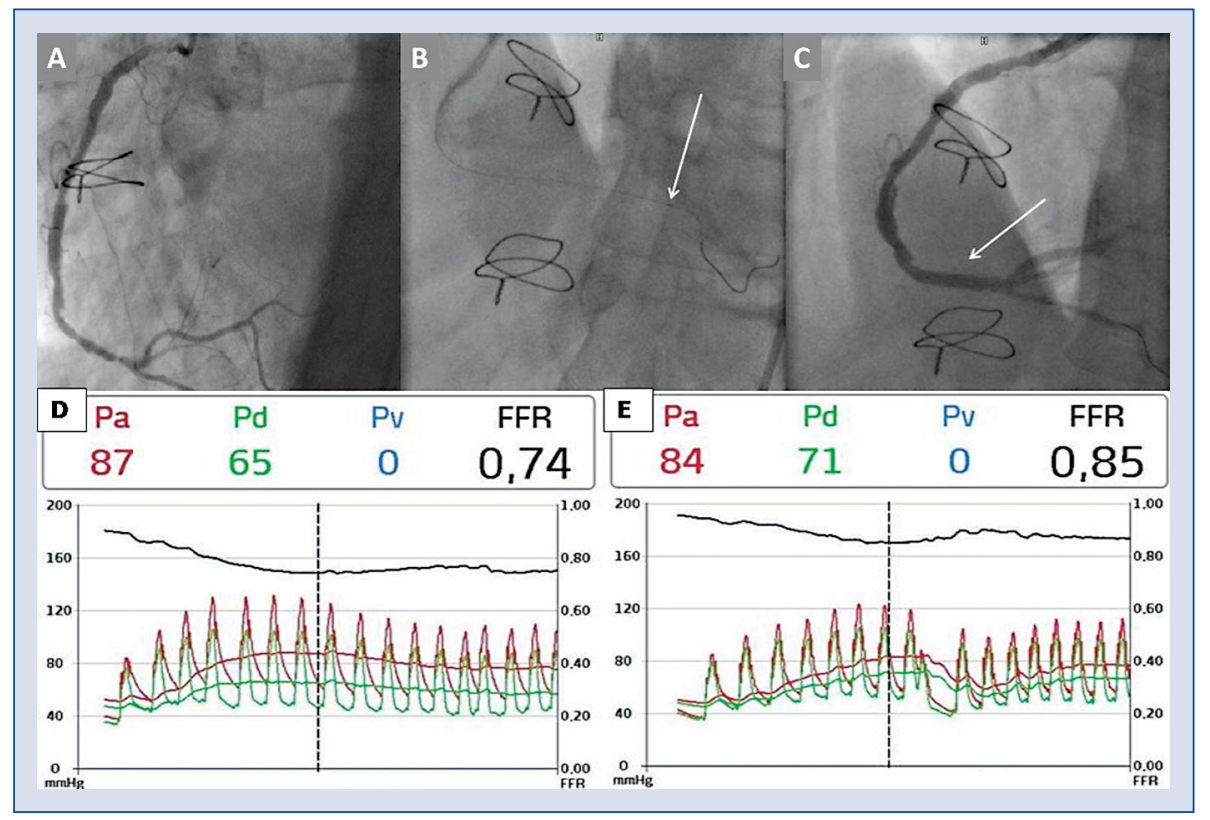

Figure 1. Fluoroscopic images of the right coronary artery $(R C A)$; $A$. Cine image of stenosed RCA; B. Cine image of RCA and the Acist Navvus microcatheter during the measurement, and its distal part with the radiopaque marker (labeled with white arrow); C. Cine image of RCA after angioplasty with stent deployment (marked with white arrow); D. Fractional flow reserve (FFR) of distal part of RCA before stent implantation. E: FFR of distal part of RCA after stent implantation; $\mathrm{Pa}$ - pressure proximal to the lesion; $\mathrm{Pd}$ - pressure distal to the lesion; $\mathrm{Pv}$ - coronary venous pressure.

Address for correspondence: Rafal Januszek, $\mathrm{MD}, \mathrm{PhD}, 2^{\text {nd }}$ Department of Cardiology and Cardiovascular Interventions, University Hospital, ul. Kopernika 17, 31-501 Kraków, Poland, tel: +48 12424 71 70, fax:+48 12424 71 80, e-mail: jaanraf@interia.pl 
graft (SVG Ao-Mg) graft was occluded. The Acist Navvus microcatheter (ACIST Medical Systems, Eden Prairie, MN, USA) was used to perform FFR measurements in RCA. Two intracoronary boluses of adenosine were administered during the procedure: $200 \mu \mathrm{g}$ and $400 \mu \mathrm{g}$. The final result was as follows: 0.74 confirmed the significance of RCA stenosis (Fig. 1D). Simultaneously, PCI of the distal RCA segment was performed. After predilatation with non-compliant balloon catheter $2.5 \times 15 \mathrm{~mm} 16 \mathrm{~atm}$, DES CID Cre8 (Carbostent\&Implantable Devices, Saluggia, Italy) $3.0 \times 20 \mathrm{~mm} 16 \mathrm{~atm}$ was deployed (Fig. 1B, C). Control FFR after intracoronary administration of $400 \mu \mathrm{g}$ of adenosine was 0.85 , which confirmed that culprit lesion was treated (Fig. 1E).

The FFR is recommended for the assessment of borderline coronary lesions (stenoses between $40 \%$ and $70 \%$ ) by international European cardiology societies [5]. It has been shown that FFR-guided PCI results in significantly lower rates of death and myocardial infarctions than PCI, based on angiographic assessment alone in 4-year followup [6]. The FFR-guided PCI coexisting with the optimal medical therapy is the most favorable approach in patients with stable angina, remarkably reducing the need of urgent revascularizations [7]. In individuals with disseminated, multi-segmental and borderline stenoses, the pull-back method with continuous recording of coronary artery pressure is used for FFR measurement. The gold standard is continuous intravenous adenosine infusion, whereas intracoronary infusion of adenosine bolus is a shorter modification that brings the similar proportion of stenosis when high doses of adenosine boluses are administered [8]. It was revealed that high boluses of intracoronary adenosine up to $600 \mu \mathrm{g}$ are safe for the patient [8]. Devices intended to be applied for FFR measurement are underutilized due to inconvenient usage. It could be caused by difficulties in PW delivery in tortuous and narrowed arteries and susceptibility to kinking [3]. Furthermore, $\mathrm{PCI}$ requires withdrawal of the $\mathrm{PW}$ and may cause complications due to this maneuver. The $\mathrm{RXi}^{\mathrm{Tm}}$ system is a new FFR technology, where ultrathin monorail microcatheter is a key part of the device. The RXi microcatheter could be used with different guide-wires (GWs), which are appropriate for the particular artery anatomy and morphology [3]. It is noteworthy, that the RXi microcatheter is compatible with standard 0.014" GWs. The Microcatheter Navvus is elliptically-shaped. The $0.020 " \times 0.025$ " dimensions are comparable to the diameter of 0.022 " circular-shaped wire. The fiber optic sensor is attached $5 \mathrm{~mm}$ from the distal tip and the radiopaque marker $2.5 \mathrm{~mm}$ from the distal tip [4]. The RXi microcatheter has a significant advantage in creating the possibility to obtain measurements without loss of wire access to the artery [4]. The FFR measured after coronary stenting is a clinically important tool to evaluate the results of the coronary intervention. However, the measurement of FFR after stent implantation requires re-crossing the stent with $\mathrm{PW}$ which entails a significant risk of its incorrect position or, in the case of stenting by PW itself re-connecting the FFR system, increases the likelihood of signal drift. RXi microcatheters allow the FFR measurement after revascularization using the same wire which was used during stent implantation, eliminating the need to recross the coronary artery or to disconnect the FFR system. Moreover, if it is necessary to re-place the RXi microcatheter in the vessel, there is no need for re-calibration [4]. Some doubts may arise if the larger diameter affects FFR value. A recently published study from New Zealand showed no influence of the Navvus Microcatheter's dimensions on the results obtained by FFR. In addition, a good correlation between the results obtained with the new method and a standard PW was noticed [3]. However, the larger diameter of the catheter may cause some difficulties with passing to the peripheral part of narrowed, calcified and tortuous arteries as compared to PWs alone, which may in some cases limit the use of RXi microcatheter.

\section{Conflict of interest: None declared}

\section{References}

1. Pijls NH, De Bruyne B, Peels K et al. Measurement of fractional flow reserve to assess the functional severity of coronary-artery stenoses. N Engl J Med, 1996; 334: 1703-1708.

2. Legutko J, Jąkała J, Mrevlje B et al. Fractional flow reserve-guided myocardial revascularization. Post Kardiol Interw, 2011; 7: 228-241.

3. Menon M, Jaffe W, Watson T, Webster M. Assessment of coronary fractional flow reserve using a monorail pressure catheter: The firstin-human ACCESS-NZ trial. EuroIntervention, 2015; 11: 257-263.

4. Diletti R, Van Mieghem NM, Valgimigli M et al. Rapid exchange ultra-thin microcatheter using fibre-optic sensing technology for measurement of intracoronary fractional flow reserve. EuroIntervention, 2015; 11: 428-432.

5. Wijns W, Kolh P, Danchin N et al. Task Force on Myocardial Revascularization of the European Society of Cardiology (ESC) and the European Association for Cardio-Thoracic Surgery (EACTS); European Association for Percutaneous Cardiovascular Interventions (EAPCI), Guidelines on myocardial revascularization. Eur Heart J, 2010; 31: 2501-2555.

6. De Backer O, Biasco L, Lønborg J et al. Long-term outcome of FFR-guided PCI for stable coronary artery disease in daily clinical practice: A propensity score-matched landmark analysis. EuroIntervention, 2016; $11: 1257-1266$.

7. De Bruyne B, Pijls NH, Kalesan B at al.; FAME 2 Trial Investigators. Fractional flow reserve-guided PCI versus medical therapy in stable coronary disease. N Engl J Med, 2012; 367: 991-1001.

8. Leone AM, Porto I, De Caterina AR et al. Maximal hyperemia in the assessment of fractional flow reserve: Intracoronary adenosine versus intracoronary sodium nitroprusside versus intravenous adenosine: The NASCI (Nitroprussiato versus Adenosina nelle Stenosi Coronariche Intermedie) study. JACC Cardiovasc Interv, 2012; 5: 402-408. 